\title{
EEG ANALYSIS OF REAL AND IMAGINARY ARM MOVEMENTS BY SPECTRAL COHERENCE
}

\author{
Nurhan GÜRSEL ÖZMEN
}

Received: 11.09.2020; revised: 02.01.2021; accepted: 23.01.2021

\begin{abstract}
Revealing the information between similar patterns of brain for a real motor task and its imaginary equivalent can be means to clarify movement intentions and help to improve Brain Computer Interfaces (BCI)s. This paper uses spectral coherence to assess the functional interactions between neural regions engaged in a real and an imagined arm movement task. Magnitude squared coherence values were calculated for two specific bands of Electroencephalogram (EEG) that are 8-12 $\mathrm{Hz}$ alpha band and $13-20$ $\mathrm{Hz}$ beta for 48 channels from selected regions of interest (ROIs). The coherence values are transferred into surface maps. We try to explain how motor cognition in these regions are relevant with the literature. The maximum coherence is observed between the channels in the same hemisphere and surrounding closest channels located vertically and horizontally based on the 10-20 electrode placement.

Our results that the supplementary motor area, the premotor, prefrontal, primary motor cortex and the parietal cortex play a role in facilitating real and imaginary motor movements, are in good accordance with the previous studies. Further research can be put on spectral coherence patterns which would be a possible means for prosthetic-interactive BCI systems, interactive multimedia applications, and emerging EEGbased biometric recognition areas.
\end{abstract}

Keywords: EEG, Spectral coherence, BCI, Motor task classification, Real and imaginary arm movements

\section{Gerçek ve Hayali Kol Hareketlerine ait EEG verilerinin Spektral Koherens Yöntemiyle Analizi}

Öz: Gerçek bir motor görev ve onun hayal edilmesi arasındaki benzer aktivasyon örüntülerinin tanımlanması, beyindeki hareket niyet noktalarının tespit edilmesine ve Beyin Bilgisayar Arayüzlerinin (BBA) geliştirilmesine yardımcı olabilir. Bu çalışmada, gerçek ve hayali bir kol hareketi görevi yapan nöral bölgeler arasındaki fonksiyonel etkileşimler, spektral koherens yöntemi ile değerlendirilmiştir. Çift kat güçlendirilmiş koherens değerleri, tipik alfa $(8-12 \mathrm{~Hz})$ ve beta $(13-20 \mathrm{~Hz})$ frekans bant aralı̆̆ında seçilen ilişkili bölgedeki (IB) 48 farklı Elektroensefalogram (EEG) kanalı için hesaplanmıştır. Farklı görevler için hesaplanan koherens değerleri, yüzey haritalarına dönüştürülmüştür. $\mathrm{Bu}$ bölgelerdeki motor biliş anlayışımızın sağ ve sol kol ile ilgili literatürden elde edilen bulgularla nasıl ilişkili olduğu açıklanmaya çalışılmıştır. Aynı yarımküredeki kanallar ile 10-20 elektrot yerleşimi temelinde dikey ve yatay olarak yerleştirilmiş en yakın kanallar arasında maksimum tutarlılığın gözlendiği gösterilmiş̧ir.

Çalışmamızın sonuçları, literatürde yer alan tamamlayıcı motor alanının, premotor, prefrontal ve primer motor kortekslerinin ve parietal korteksin gerçek ve hayali motor hareketlerini kolaylaştırmada rol oynadığı bulguları ile uyumludur. Çalışmanın sonuçları, spektral tutarlılık modellerinin protez-etkileşimli BBA sistemleri, etkileşimli multimedya uygulamaları ve ortaya çıkan EEG tabanlı biyometrik tanıma alanları için olası bir araç olabileceğini göstermektedir.

Anahtar Kelimeler: EEG, Spektral koherens, BBA, Motor görev sınıflandırma, Gerçek ve hayali kol hareketleri

\footnotetext{
* Dr. Nurhan GÜRSEL ÖZMEN, Karadeniz Technical University, Department of Mechanical Engineering 61080 Trabzon TURKEY

Correspondence Author: Nurhan GÜRSEL ÖZMEN (gnurhan@ktu.edu.tr)
} 


\section{INTRODUCTION}

In neuroscience studies, the variations in the brain due to a particular effect or of interest are the main concern of researchers. These changes can be represented with oscillatory power, with source activation or with inter-regional functional connectivity measures. However, it is a challenging work to find interrelated areas among the mysterious working of the brain. For this reason, researchers have selected particular tasks with the corresponding regions of the brain based on the previous medical findings (Mamashli et.al.,2019).

Recent studies put a great concern on the motor functioning of primary and the supplementary motor areas of the brain. However, there are still some findings on motor movement and motor imagery. Studies of brain activity have shown that brain conditions change during certain cognitive functions or mental states, such as reactions given a visual or audible stimulus (Lima et.al.,2016), or real or imaginary limb movements (Sleight et.al.,2009, Ozmen and Gumusel, 2013, Yong and Mennon 2015), imaginary speech (Zhang and Zhao,2013), relaxed situations and emotional states (Wang et. al.,2014), (Li et. al. 2019),(Ozel et. al. 2019). The morphological, anatomical and the functional plasticity characteristics of the change can be inferred from the Electroencephalography (EEG) data. Thus, EEG containing cortical potentials in various mental or motor states can be used to actuate a brain computer interface (BCI) system. Wolpaw et.al.,2009, defined the main objective of a BCI system as providing an alternative communication facility for humans with neuromuscular diseases. The efficient operation of BCI systems depends on the correct identification and classification of the recorded EEG signals. A clear demonstration of the physiological interaction in the brain gives rise to the correct identification and classification of electrical potentials that vary instantaneously during different mental and motor tasks (Ozmen et.al.,2018). To this end, many studies were conducted from different perspectives for the interpretation of cortical activity to drive a BCI system efficiently (Daly et.al.,2012), (Nicolelis,2003), (Mühl et. al., 2014), (Neuper,2006).

Most of the human behaviors involve motor activities, like standing, walking, talking and even very small movements. But every single move like stretching a finger can be a complicated motor cognition task in the brain. Motor skills processing of brain is a multidirectional phenomenon, containing different mechanisms that can interact in a complex way. The primary motor cortex (M1) is known for being responsible for coordinating voluntary muscle movements Moreover, it was also reported that imaginary movements also activate M1. Researchers studied the inclusion of primary motor area and supplementary motor area in these mechanisms. They showed that movements and intentions are closely related and inferior frontal, central, and posterior parietal regions (URL1) are in charge. Moving the arm from one point to another starts by transforming sensory information into motor commands which are in a special style. This phenomenon occurs by combining the sensory signals of the goal and those defining the position of the arm. This process should be entirely applied to neuroprostheses and BCI applications.

The high frequency cortical oscillatory brain activity can be represented by magnetoencephalographic (MEG) recordings, functional magnetic resonance imaging (fMRI) recordings and with also EEG recordings during cognitive tasks and sensory stimulation (Galambos et al., 1981, Basar et al., 1992, Tzelepi et.al.,2000, Sannita et al., 1995, Sasai et.al.,2020, Fu et.al., 2020) . Bundy et.al (2018) performed three-dimensional, individual arm motions by usin fMRI recording technique and they have observed that the neural activity from a single arm movement show similar patterns in the right and left hemispheres. Ames et.al. (2019) performed magnetic resonance imaging (MRI) with monkeys on neural recording and they showed that motor cortex signals for each arm are mixed across hemispheres. They concluded that the activity related to each arm occupies a distinct subspace and the signals related to the other arm are naturally eliminated. 
In most of the previous studies, the conventional power spectral density (PSD) is used to exhibit the parallel arranged cortical cell activity and a physiologically average value over cortex is calculated (Ozmen et.al., 2018), (Akin and Kiymık,2000), (Seleznov et.al.,2019), (Seeber, et.al.,2000), (Nunez et.al. 2001). In (Lopes,2013), (Tzelepi et.al.,2000)'s works they have stated that the amount of power in different frequency bands is correlated with the task specific activities. Many EEG studies were conducted to discriminate the multitask problems in frequency domain. This method is useful however, EEG PSD addresses the single-channel behavior and cannot characterize the connection between various EEG channels, i.e. the interconnection among different sites of the brain. In this case, temporal relations between the recorded EEG signals can be neglected. Hence, it is extensively reported that the execution of goal directed movements are achieved by intra and interelectrode regions. Besides PSD, EEG coherence emerged as a high valued method to identify functional cortical connections of various cortical regions of the brain (Pereda et.al.,2005), (Dauwels et.al., 2010b),(La Rocca et.al., 2014). Coherence value is linearly proportional with the synchrony between the signals. Tang et.al.,2019, Baccala and Sameshima, 2001, searched the functional interactions of neural signals between neural regions by using coherence and partial coherence analysis which were gathered in the frequency domain. The coherence is a metric used to diagnose the phase stability of two signals of a specific frequency. It is mainly used to represent the interconnectivity, which defines the value of relation between the signals of two electrode placements. A meaningful statistical power is obtained during different tasks of interest for selected frequency bands which are alpha $(8-12 \mathrm{~Hz})$ and beta (1330Hz) (Bezerianos,2007).

As far as we searched, there is no article relating spectral coherence metrics of motor tasks about arm movements on a broad ROI. In most of the neuroscience studies, coherence is used to quantify the relations across various brain areas that are connected with functional connectivity (Gao et.al.,2011),(Sugata et.al.,2016),(Kilner et.al.,2004) or motor movement intensions (Yang and $\mathrm{Lu}, 2018$ ). In this paper, we prepared a motor movement task with right- and left-hand to examine the EEG neural changes and discuss the engagement of primary and the supplementary motor areas across a real and imagined arm movement task which is the novelty of the study. PSD and spectral coherence characteristics corresponding to right- and left-arm movement and imagination are analyzed. To this end, two goals have been identified:

- G1: Examination of spectral consistency between real and imaginary tasks themselves in selected ROIs.

- G2: Examination of spectral coherence between real and imaginary tasks in the selected ROIs.

The titles studied in this study can be used in prosthetic-interactive BCI systems, interactive multimedia applications, and emerging EEG-based biometric recognition areas.

The remainder of this paper is organized as follows. The experimental procedure and the method is explained in Section 2. In Section 3, the EEG processing and the results of EEG coherence measures are presented. In Section 4, results are discussed by comparing the previous works. Section 5 is the conclusion part.

\section{MATERIALS AND METHOD}

Two healthy male participants with mean age of 20.5 years who did not have any neurological, psychological, chronic illnesses voluntarily joined to this study. Participants were right-handed according to the Edinburgh Inventory. Participants have signed the Informed Consent Protocol. The experimental protocol and procedures were in compliance with the 
declaration of Helsinki. The experiments have been conducted at Karadeniz Technical University, Department of Mechanical Engineering, Trabzon, Turkey.

\subsection{Recording Steps}

Participants sat on a relax armchair in a daylight illuminated, plain and quiet room during the experiments. They were requested to minimize eye blinks and body movements during the experiment. The experimental paradigm and the whole recording steps, the starting and ending times are explained by the researcher before the measurements. The experimental session is designed to be four parts. In the first part, the subject was taught to make a right arm task, which contains moving the arm to the right and left in a moderate velocity consecutively. The second part is the movement of the left arm to the right and left consecutively. The third part passes to the imagery arm movements. Volunteers were taught to imagine the right arm movements similar to the real case. Participants were told to just imagine the kinesthetic of the movement and not the visual image of the act itself. In each session, five movements were recorded. Each trial contains a 10 second recording, 8-10 second intervals between consecutive trials were given to prevent fatigue. For four different tasks, 100 consecutive recordings were performed on different days. The order of execution of the tasks is the same for all participants and for all recordings. For both arms, the actual arm movement was recorded first, and then the imaginary arm movement. Because, execution of arm movements firstly will make it easier for the user to imagine that move. The tasks are explained and labeled as below for the further part of the study.

Right arm movement task (Task 1): It is the task of executing right arm consecutively to the right and left sides.

Right arm imagination task (Task 2): Imagining ongoing movement of right arm as in Task 1.

Left arm movement task (Task 3): It is the task of executing left arm consecutively to the right and left sides.

Left arm imagination task (Task 4): Imagining ongoing movement of left arm as in Task 3.

\subsection{EEG Preprocessing}

In an EEG experiment, a headcap, electrodes and recording device is necessary. Brain's electrical activity is recorded by various electrodes mounted to the scalp of a participant at predefined positions. Each location is indicated with letters inferring brain areas (e.g., F for frontal), and numbers showing lateral arrangement (odd numbers attained for left, even numbers for right). We used a 64 channel Biosemi ActiveTwo EEG system, and the recordings were performed based on international 10-20 electrode placement system with a Biosemi head cap (Biosemi, Amsterdam, NL). The positions of all the electrodes and nasion, inion and the two preauricular points were precisely measured for each subject. Ground electrodes Common Mode Sense (CMS) active electrode and Driven Right Leg (DRL) passive electrode were stacked to the relevant places at the occipital lobes (See Figure 2). The sampling frequency of EEG signals was arranged as $512 \mathrm{~Hz}$. The signals measured from each site are amplified, and formed as raw signal of each channel. In EEG recordings, voltages recorded at each electrode are computed with reference to another electrode for fine measurements. $\mathrm{Cz}$ channel is a reliable and common selected reference which is also used in this study. All the impedances of signals were tuned to be bellow $5 \mathrm{~K} \Omega$. Then a bandpass filter is applied to the signals between 0.5 and $50 \mathrm{~Hz}$.

\subsection{Channel Selection}

Brain activity recorded from one electrode can be a strong signal, and can be affected by the nearby electrodes (Holsheimer and Feenstra,1977), (Nunez et.al.,1997). Volume conduction is one of the reasons that mix different sources of electrode channels. Based on the complex functioning mechanism of the brain, several activities take place at different positions, and these activities can be synchronized. As a matter of fact, similar signals can be recorded from different 
sites of the brain (Figure 1). In order to reveal the basic functioning of each region of brain, people generally focused on places from past scientific literature. A specific area can manually be selected for each subject, and ongoing experiments can be conducted for user defined activities for a specific frequency range e.g. alpha $(8-13 \mathrm{~Hz})$ and beta $(13-30 \mathrm{~Hz})$ bands. In this study, three ROIs were selected for analysing the task dependencies (Figure 2) based on existing anatomically motor task execution and motor task planning facts as in literature (Yong and Menon,2015, Sugata et.al.,2016, Sasai et.al.,2020). The data from Frontal-F " $F p 1, F p 2, F p z, A F 3, A F 7, A F z, A F 4, A F 8$, $F 5, F 3, F 1, F z, F 2, F 4, F 6$ ", Sensorimotor - "FC5, FC3, FC1, FCz, FC2, FC4, FC6, C5, C3, C1, $C 2, \quad C 4, C 6, C P 5, C P 3, C P 1, C P z, C P 2, C P 4, C P 6$ ", and parietal- $\mathrm{P}$ " $P 7$, $P 5, P 3, P 1, P z, P 2, P 4, P 6, P 8, P O 7, P O 3, P O z, P O 4, P O 8$ " channels are analysed. It is advised to select these ROIs anatomically small to cancel temporal signal interactions.

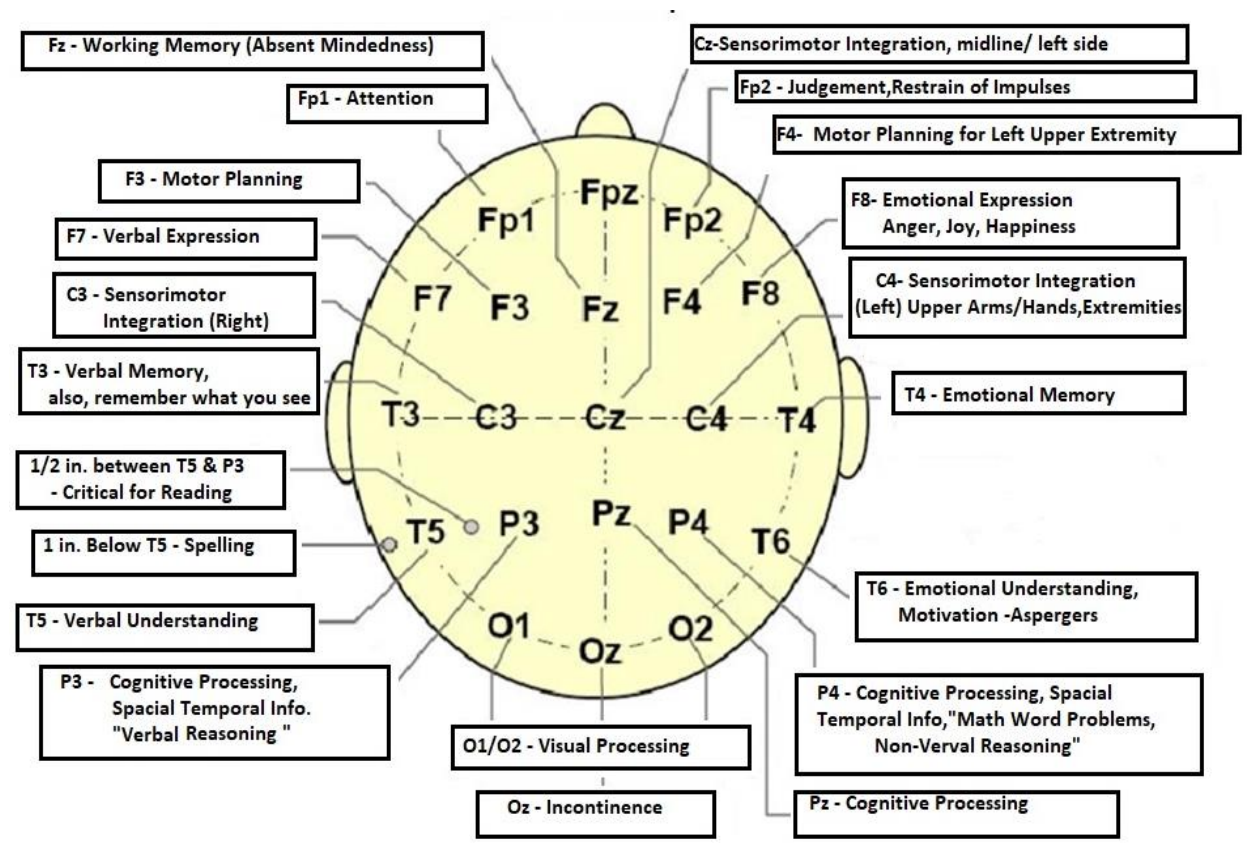

Figure 1:

Brain task map 〈(URL2)> 


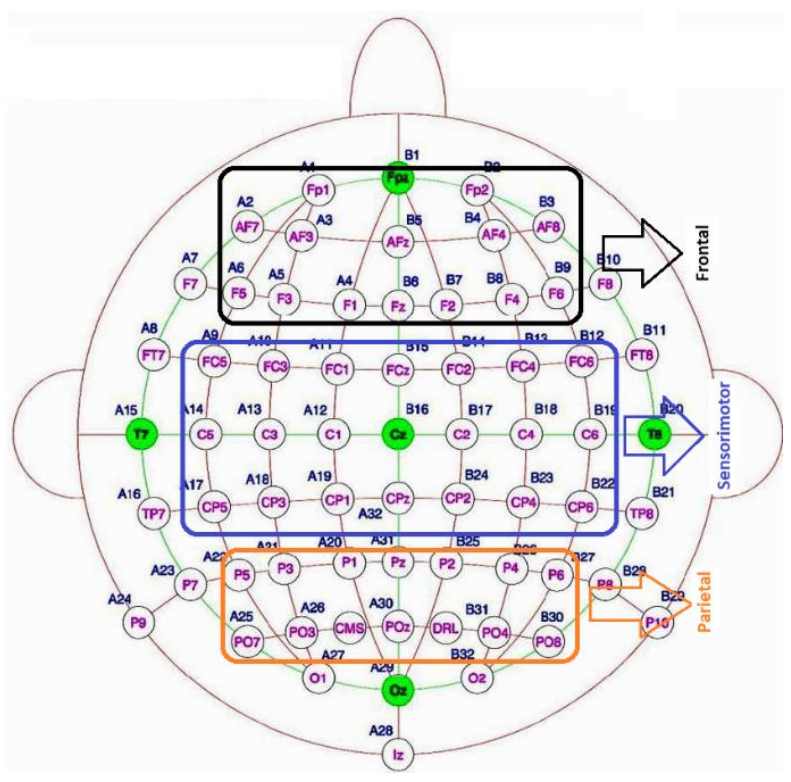

Figure 2:

Selected ROIs on Biosemi 64 channel system

\section{EEG DATA ANALYSIS}

The recorded raw data were visually examined for noisy trials and none of the data were excluded. A mean of 100 trials was obtained for each channel and task, so that the analyses were performed on that signal. The data were analyzed in the $1-30 \mathrm{~Hz}$ frequency range. Because, while healthy people are awake, the actual activity is in the range of $8-13 \mathrm{~Hz}$ alpha and $14-30 \mathrm{~Hz}$ beta for motor tasks (Holsheimer and Feenstra,1997). The effect of higher frequencies is omitted.

\subsection{Spectral Coherence}

Coherence analysis is a popular statistical technique which has been applied to multichannel EEG data for understanding linear coupling between signals. It shows the synchrony between two signals or data sets as a quantitative value. In signal processing, it is defined as the frequency form of time domain autocorrelation function which typifies the normalized covariance of two time series in the frequency domain. Moreover, it shows the linear dependence between a pair of signals and is represented by normalizing the values between zero and one.

The PSD of a signal shows how power of a signal or time series is distributed over frequency. When a function over time $x(t)$ is the voltage across a unit resistor, the instantaneous power in the signal $\mathrm{x}(\mathrm{t})$ is obtained by $x^{2}(t)$. When $x(t)$ is wide-sense stationary, the expected instantaneous power is calculated by ;

$$
E\left[x^{2}(t)\right]=R_{x x}(0)=\frac{1}{2 \pi} \int_{-\infty}^{\infty} s_{x x}(j w) d w
$$

$s_{x x}(j w)$ is called the power spectral density of $x(t)$, and it is the Fourier transform of the autocorrelation function $\operatorname{Rxx}(t)$.

The mathematical form of coherence is calculated like cross-correlation coefficient in the frequency domain at a specific frequency (Halliday et.al.,1995), (Wang et.al.,2015). The 
magnitude-squared coherence is calculated as a function of the power spectral densities,. Sxx(f) and Syy(f), and the cross power spectral density, Sxy(f), of $x$ and $y$.

$$
C_{x y}(f)=\frac{\left|S_{x y}(f)\right|^{2}}{S_{x x}(f) S_{y y}(f)}
$$

The spectral coherence represented with $C x y(f)$ becomes 0 if there is not a synchronization among two signals at the specified frequency $f$. If there is maximum linear correlation, then the value is 1 . Spectrum values in Eq. (1) $S x y(f), S x x(f)$ and $S y y(f)$ are calculated by using Welch mean modified periodogram in Matlab.

The computation of magnitude-squared coherence was done on a specified frequency band such as alpha and beta bands. Firstly, a whole spectrum was computed and then zoomed into the range of interest between 7-25 Hz. Moreover, a value of 1 or a closer digit represents high cooperation between EEG signals and a densely information transfer between the surrounding hemispheric brain areas. So that, people have used coherence estimation as a convenient measure to track and quantify the synchrony characteristic of two particular frequency band EEG series (Dauwels et.al.,2010b), (Pereda et.al, 2005), (Manganotti et.al.,1998), (Güntekin and Başar,2010), (Güntekin et.al.,2017).

The degree of interaction between two signals among elements of different channels is a criterion for the analogy of signals. The coherences among the elements of each ROIs were investigated. In addition, the coherences between elements of different ROIs were also searched to examine the interrelationship between right-left hemispheres and ROIs.

In this study, a $48 \times 48$ (48 is the number of selected EEG channels) matrix is generated by calculating each electrode pair individually. Therefore, a table is formed for each frequency band that shows the connectivity between all possible functionally independent brain regions.

\subsection{Coherence Findings}

In this section, based on the above theoretical background and mathematical equations, power spectral densities and following coherence values of EEG data were calculated for the alpha (8-12 $\mathrm{Hz})$ and beta $(13-30 \mathrm{~Hz})$ frequency ranges for 48 scalp positions. They were all obtained for the real and imaginary arm movement tasks. The maximum coherence values corresponding to each channel were computed first and then these values were converted to surface maps in Matlab in order to enrich their expressions. A sample maximal coherence value obtained for a selected channel is given in Figure 3. The value which corresponds to the highest peak within alpha or beta band is selected as the coherence value. Table 1 presents the interaction between the selected 15 channels of Frontal ROI. The far most left column represents the selected tasks and following two columns represent the coherence values between the selected channels of ROIs. S1 serves for subject 1 and S2 serves for subject 2. The values on the diagonal of coherence matrixes are all 1, which represent the complete synchrony with the signal itself and the level of interaction gradually changes depending on the distance between channels. In Table 1, it is clear that the coherence matrices of the two subjects are not fully coincided. However, the two subjects' coherence distributions were symmetrical for all four tasks, which might refer to the consistency of the experiments and the presence of bidirectional information transmission between related brain areas. When carefully examined, there are more yellow color areas of high values showing coherence for S2 than that of S1 in the Task1. Whereas for Task 3 and Task 4, S1 has higher coherence than S2. A strong relation between " $F 1-F 3$ " and " $F 2-F 4$ " and in prefrontal cortex " $F p 1$ $F p z, F p 2, A F 7-A F 3, A F 4-A F 8$ " is visible for Task 1. During the left hand execution and imagination, the prefrontal and frontal channels showed a perfect harmony. 


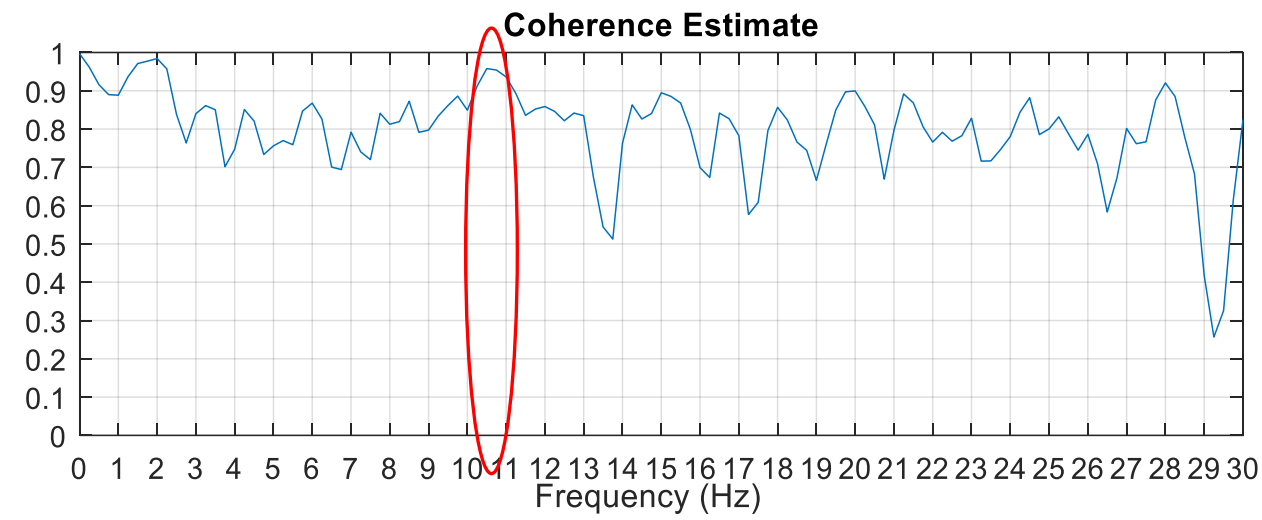

Figure 3:

Example coherence graph for FC5 -FC3 of S2

Table 1. Coherence Matrixes for Frontal ROI

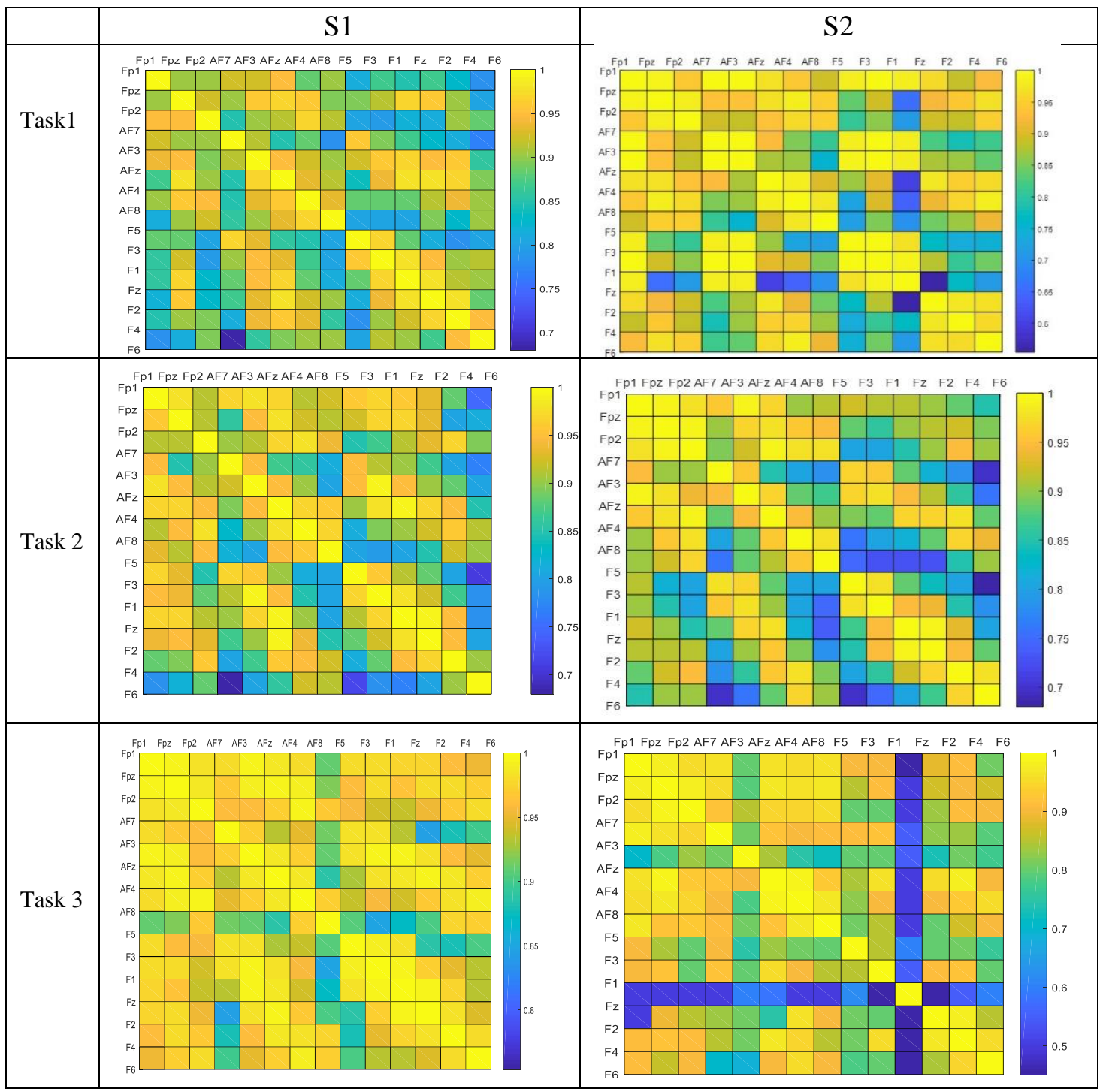




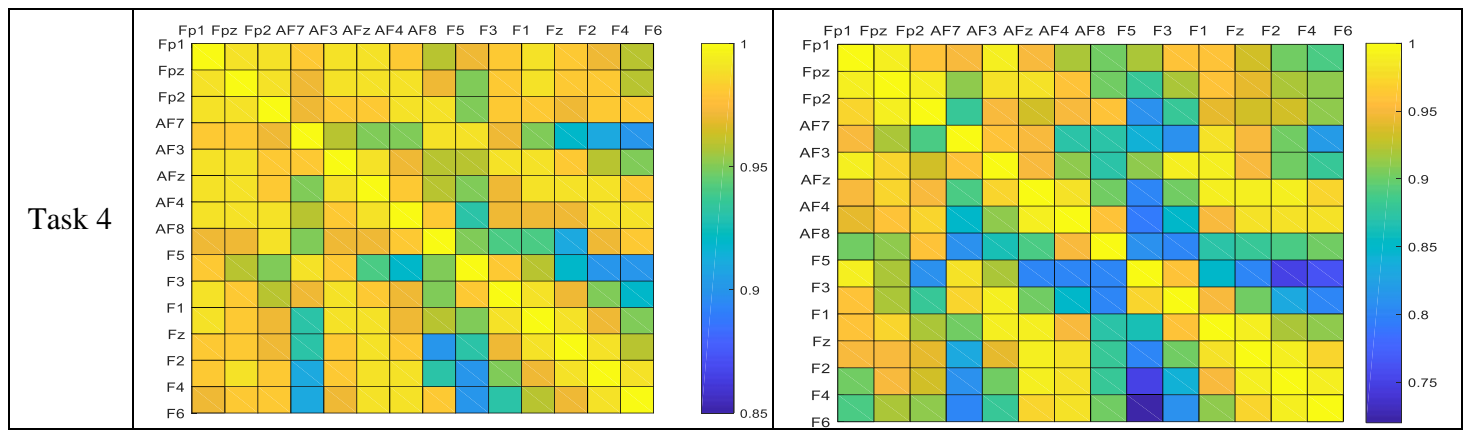

The magnitude square coherences of Sensorimotor ROI are given in Table 2. There is a clear harmony between S1 and S2 for primary motor areas during Task 1 and Task 3 which are the execution of right and left arms. There were no significant differences between real and imaginary tasks (Task1 -Task 2 and Task 3-Task 4). On the other hand, the high coherence values over right hemisphere channels (right sensorimotor area) are more visible during the left arm execution and imagery tasks (Task 3 and Task 4) for both subjects. There is a slight difference for left arm imagination (Task 4) where the sensorimotor integration is triggered for C2-C4-C6.

Table 2. Coherence Matrixes for Sensorimotor ROI

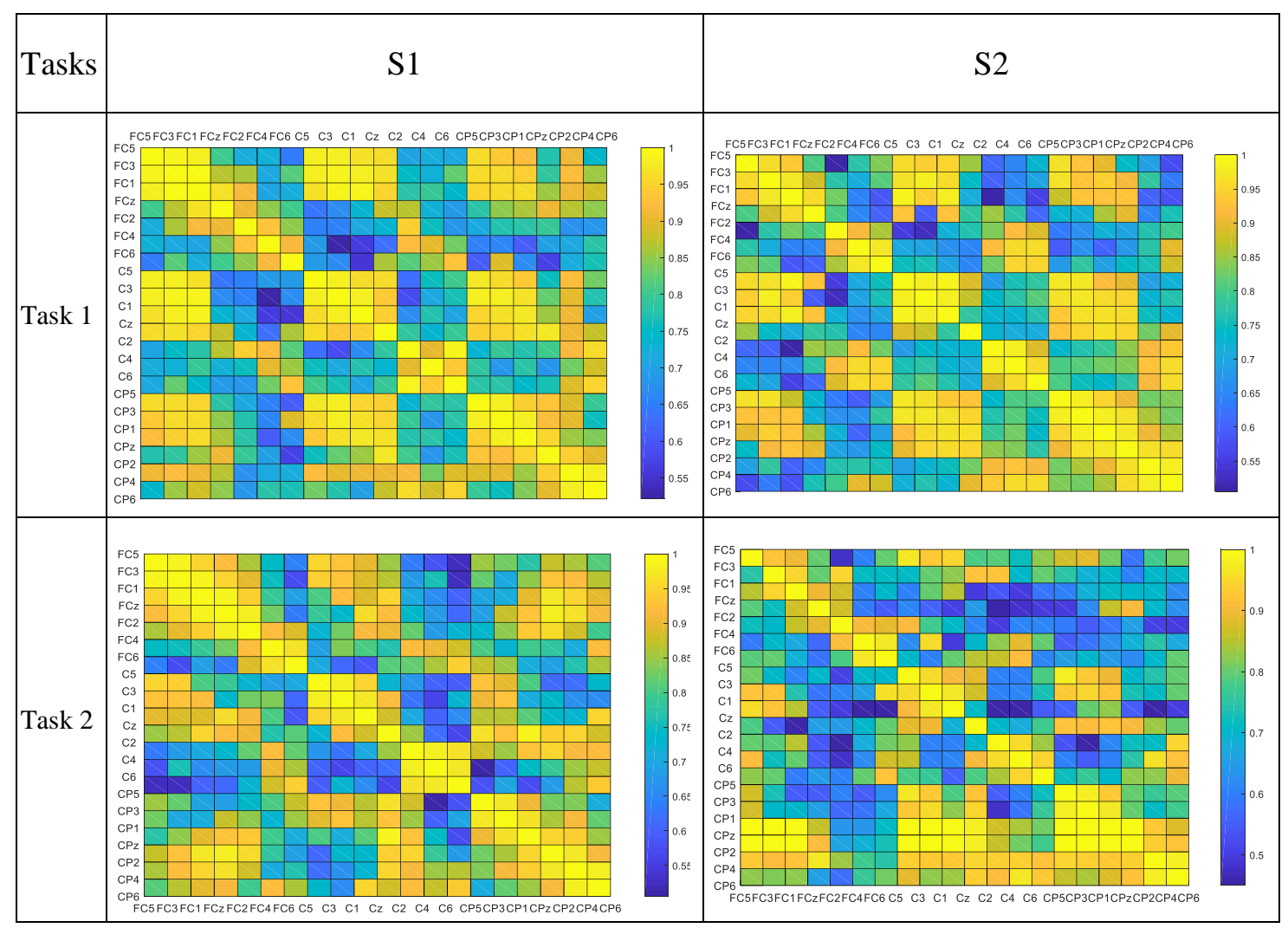




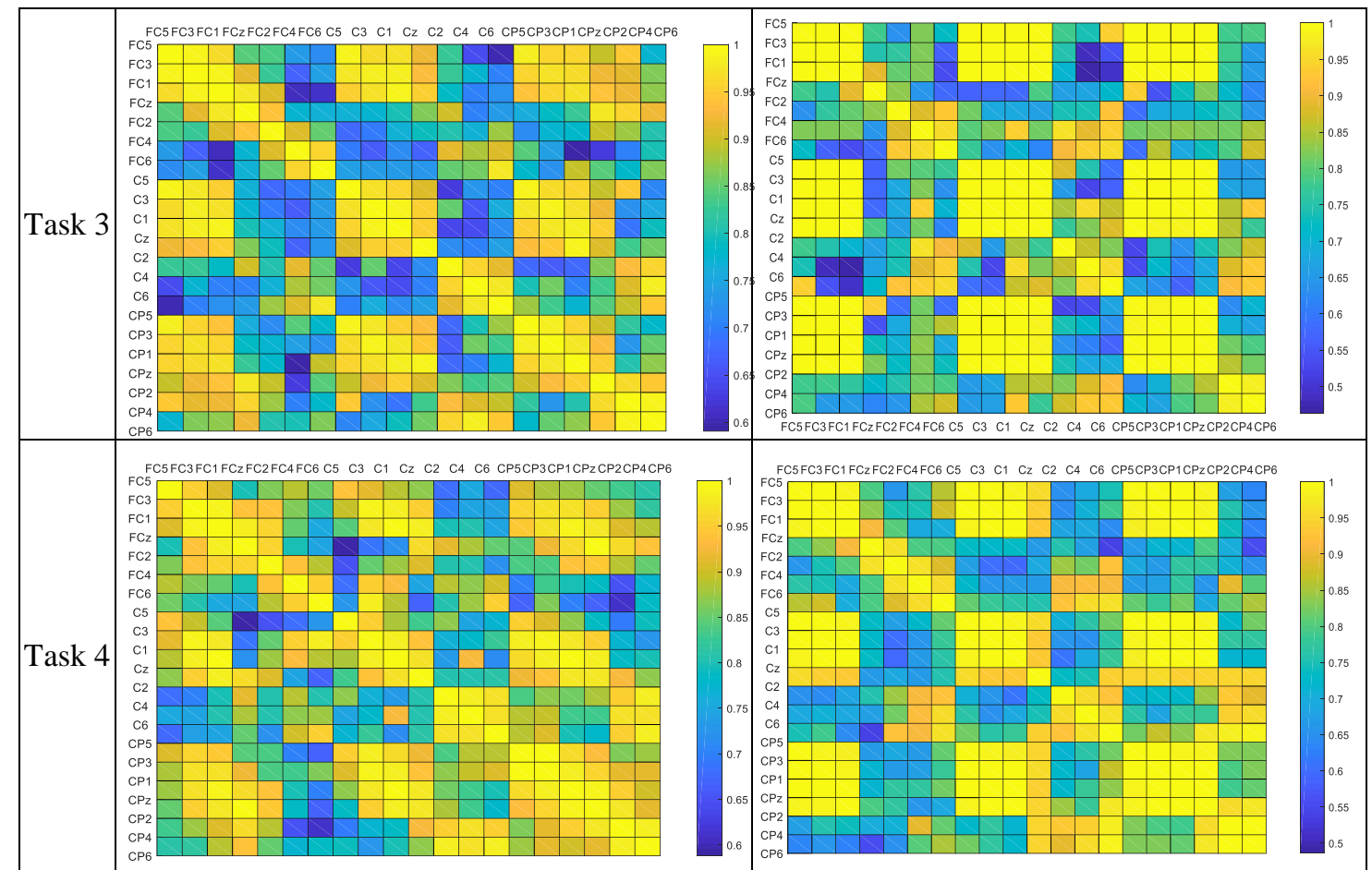

The magnitude square coherences of Parietal ROI are given in Table 3. The coherences between "P1-P3-P5" and "PO7-PO3-POz" are apparently high for Task 2 and Task 4 especially for S1. S2 has similar patterns with lower coherence values. On the other hand, for Task 2 and Task 4, the effect of visual imagery is observed which you can detect from the yellow color of "PO4$\mathrm{PO} 8-\mathrm{POz}$ ". According to these obtained results of bilateral activation of sensorimotor areas, there is a clear consistency with the previous findings during right hand and left hand tasks (Gao et.al.,2011).

Table 3. Coherence Matrixes for Parietal ROI

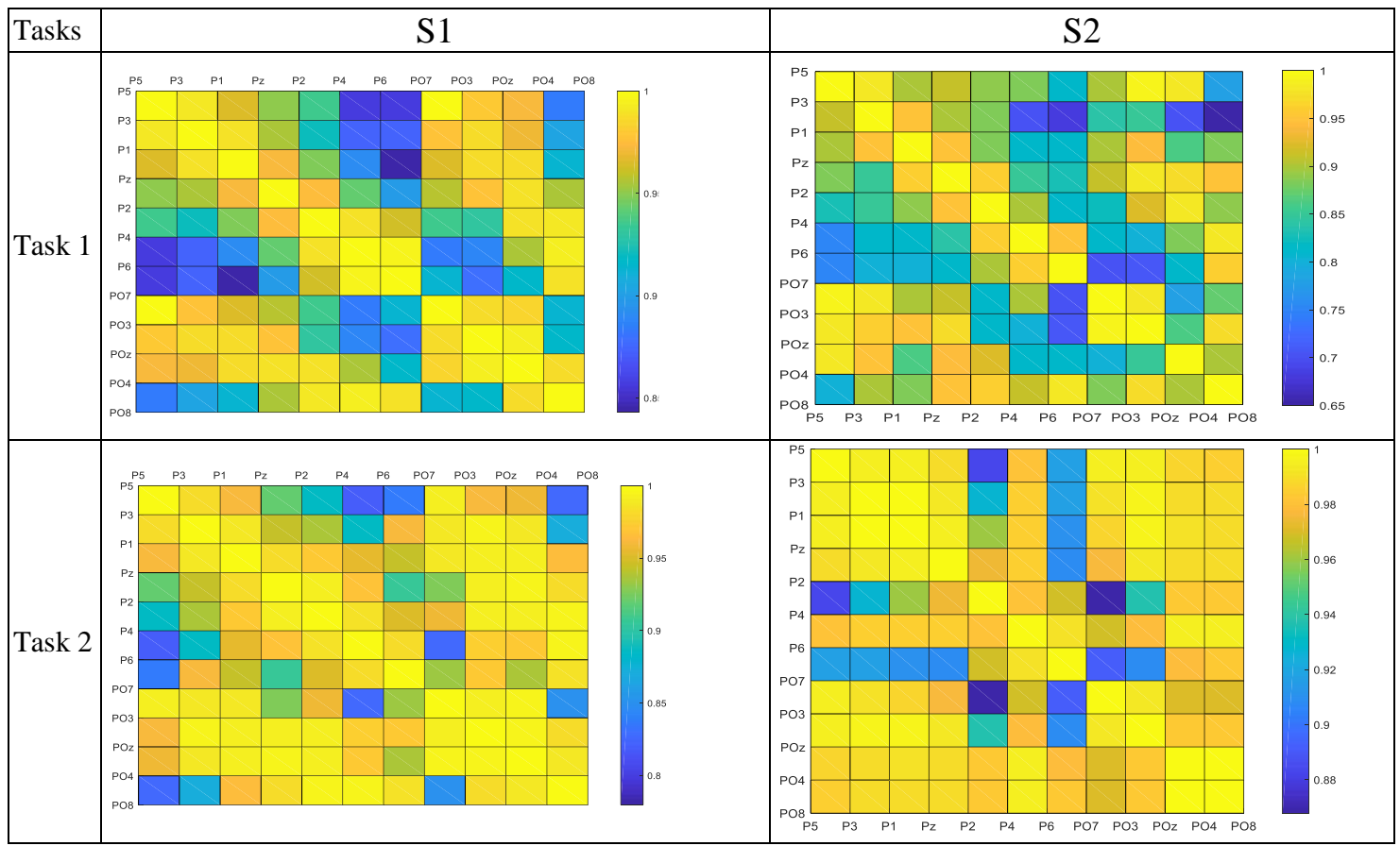




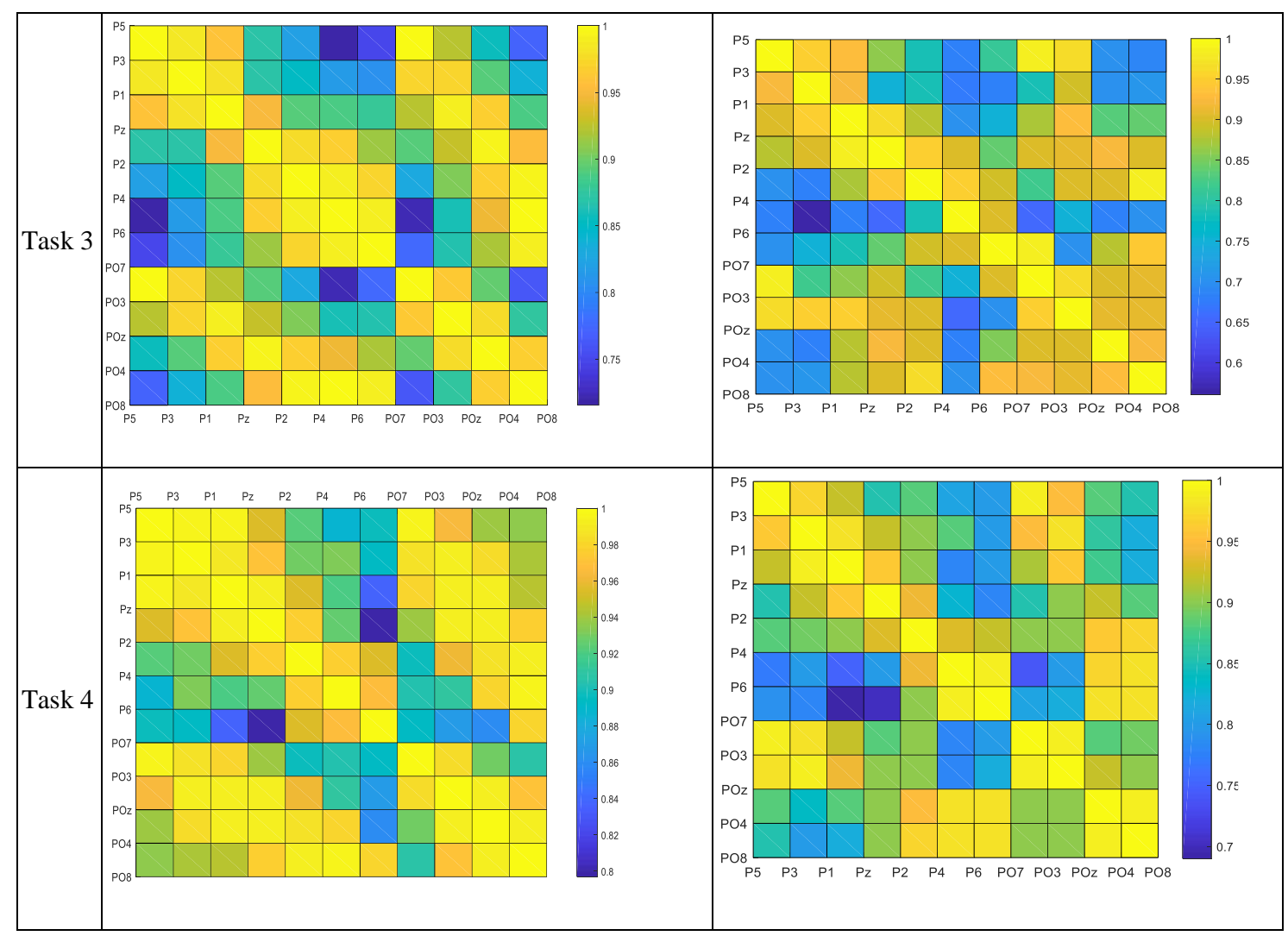

To investigate the relation between real and imagined right arm movements, magnitude squared coherences were calculated for each ROI and presented in Table 4. There is no good match between real and imagined tasks in frontal regions especially for S1. S2 has bilateral symmetry around " $A F 3-A F 7$ " and " $F z-F 1-F 3-F 5$ " channels. For sensorimotor region, during Task1/Task2, S1 has highest coherence values around " $C P z-C P 2-C P 4-C P 6$ ". However, for S2, sensorimotor region " $F C 1-F C 3-F C 5, C 5-C 3-C 1-C z$ " and "CP5-CP3-CP1-CP $z$ " have the highest coherence values for all tasks and for $\mathrm{S} 1$ for only Task3/Task4. This can be a similar attitude for both right and left arm execution and imagination. Among the parietal cortex, "P2-P4" and "PO4$P O 8$ " are in good match for both subjects. For S2, "Pz-P1-P3-P5" showed high coherence during right arm execution and imagination.

It is demonstrated that maximum coherence is observed between the channels in the same hemisphere and surrounding closest channels located vertically and horizontally based on the 1020 electrode placement. Moreover, it is observed that the spectral coherence between real and imagery motor tasks are low. Finally, we have seen that the value of decrement between pairwise electrodes is much more apparent in inter-hemispheric regions than that in intra-hemispheric regions. 
Gürsel Özmen N.:EEG Analysis of Real and Imag. Arm Movements by Spectral Coherence

Table 4. Coherence Matrixes for Movement-Imagery (Frontal-Sensorimotor-Parietal)

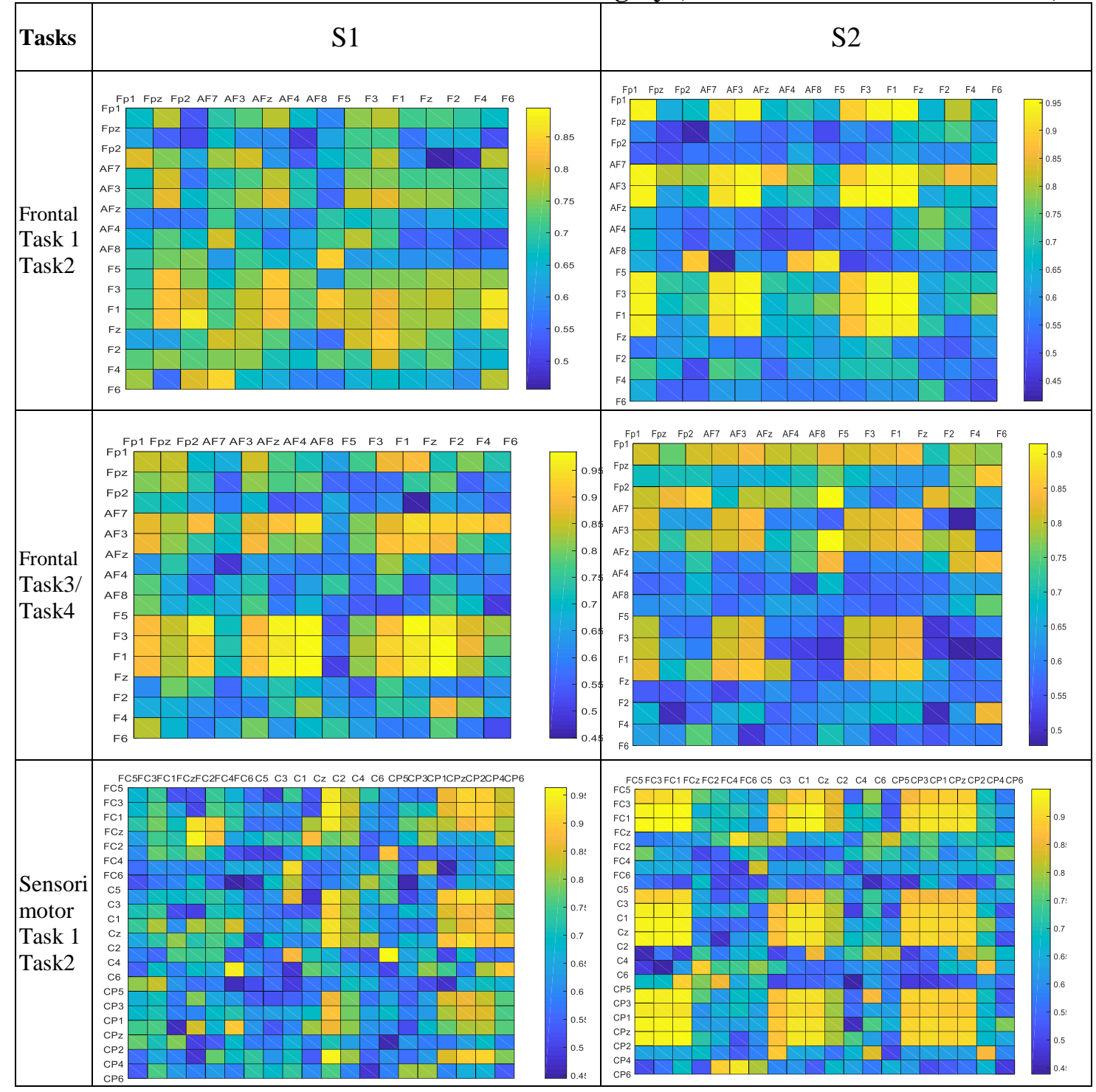

Table 4. Coherence Matrixes for Movement-Imagery (Frontal-Sensorimotor-Parietal) (Continued ...)

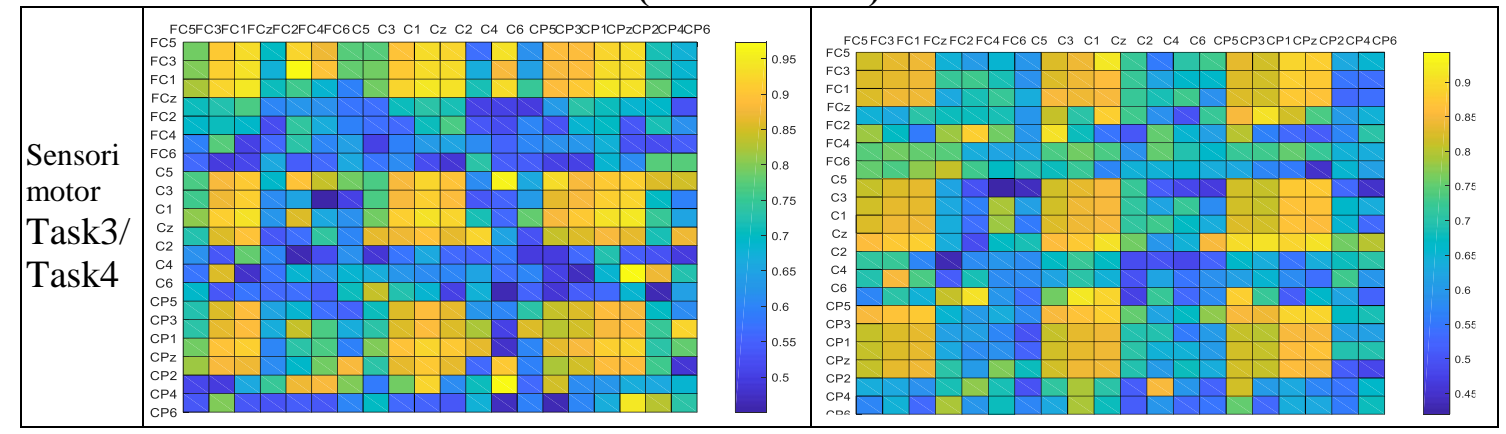




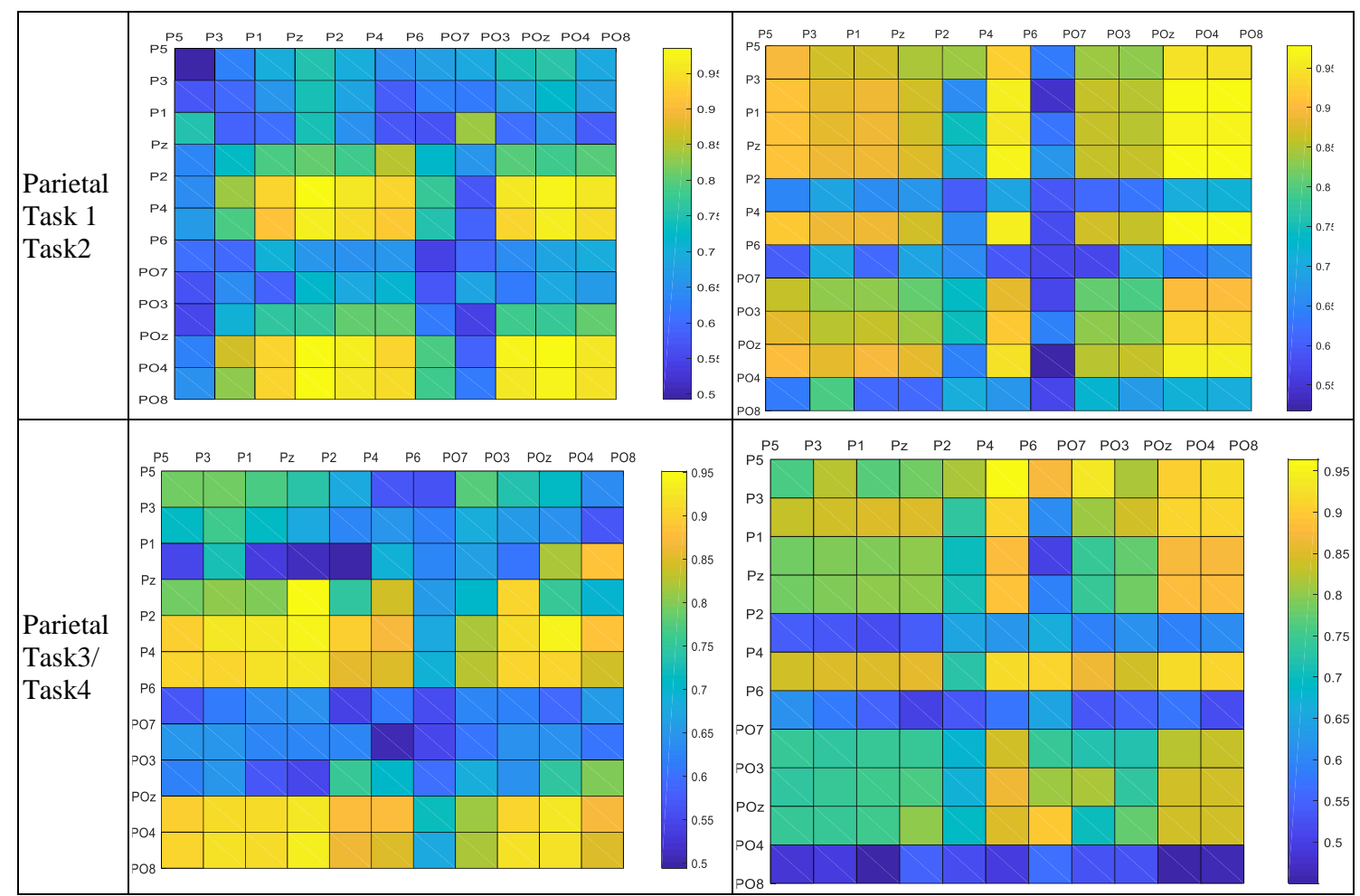

\section{RESULTS AND DISCUSSION}

This study was intended to differentiate the oscillatory patterns of brain functioning based on specific tasks during real and imaginary motor movements. We prepared four tasks for right and left arm movements to compare the results obtained for all tasks. While the previous studies (Yang and Lu,2018), (Matyas et.al.,2010),(Cheyne et.al.,2006),(Binkofski et.al.,2002) searched for the cortical activation patterns of real and imagery hand movements, the present study focused on arm movements with additional ROIs detecting the coupling between cortical regions with EEG coherence analysis. In most cases, PSD calculation between different channels and different tasks were reported. However, temporal relations between the recorded EEG signals from different sites can be neglected. We searched for the similarities and distinctions of real and imaginary tasks. Motor imagination is like simulation of a movement (i.e. kinesthetic movement replication) without physically performing it. In Matyas et.al.,2010's, Cheyne et.al.,2006's ,Binkofski et.al.,2002's and Personnier et.al.,2010,'s works, it is proved that there are mutual neurocognitive mechanisms between real (overt) and imaginary (covert) movements. In their work, it is stated that the detection of brain activity during imagined activities has arisen that the supplementary motor area, the parietal cortex, primary motor cortex, and its adjuncts that are premotor and prefrontal cortices, moreover, the basal ganglia and the cerebellum are also associated for both real and imaginary motor movements (Personnier et.al.,2010). Therefore, it's concluded that the movement execution and imagination come from common biomechanical and spatiotemporal basics and ensue the similar laws of physical control (Gentili et.al.,2004).

Bundy et. Al. (2018) recorded neural activity in both sides of the brain's cortex during the movement of only one arm in humans suggesting that the motor movement information is conserved across hemispheres, which is different than the previous idea that only the left side of the brain is responsible for movement on the right side of the body or vice versa. Ames et. Al. (2019), have shown that signals were present in both hemispheres, and signals corresponding to the two arms were naturally separable at the level of the neural population. Our results from primary motor cortex of two subjects that do not show a single hemisphere consistency can be 
explained with Bundy's idea. According to the results of this study, we can infer that there is dynamic intercommunication between different sites of brain especially mesial central, bilateral and prefrontal regions which are more active during imagery acts. These results are coherent with Gao et.al.,2011's work who showed the bilateral activation of sensorimotor areas during right hand and left-hand tasks.

In the development of neuroprothesis, signals obtained from the primary motor cortex (M1) have a major mission in controlling external medical devices. Some studies reported that during imaginary movements M1 is not included but this issue was refuted by later researchers (Georgepoulos,1989),(Miller et.al.,2010) and they reported that imaginary acts activates M1. It is also proved that the value of functional connectivity between M1 and the related motor area directly influences the productivity of BCIs in both executed and imagined tasks (Sugata et.al.,2016).

In this study, the coherence results of real and imagery arm movements of two subjects were not totally in good accordance. Because, the discrimination of motor imagery of different movements is a challenging task since those movements have close spatial representations on the motor cortex area. The experiments can be carried out with a large number of subjects to get some more convincing proofs of motor execution. On the other hand, our findings on M1 and the supplementary motor area coincide with Bundy et. Al.(2018) and Ames et. Al. (2019)'s results.

In a more broad magnetoencephalography (MEG) study (Sugata et.al.,2016), it is concluded that the consistent activity throughout real and imagery motor tasks is affected from the frontal and parietal lobe. So that these regions have major importance during both overt and covert activities. So that, in this study, we tried to put forth this relation with a very basic tool EEG and have found similar relations due to the coherence relation in the selected frontal, sensorimotor and parietal ROIs.

\section{CONCLUSION}

The present study searched for the most active brain regions during executing and imagining arms to identify the relational networks among related regions in the frontal, central and parietal lobes of brain by using magnitude squared coherence analysis which are turned into surface maps. In our results, both the coherence values and maps demonstrated the interregional relationships. Recent studies provided evidence for imagined activities involving of the exploration of brain activity that the supplementary motor area, the primary motor cortex and its adjuncts which are the premotor, and prefrontal cortices and the parietal cortex are involved. Therefore, the findings of this study are in good accordance with the recent works. In addition, based on the coherences between real and imaginary arm movements of left hand, it can be inferred that the same areas are involved during movement processing.

As a future work, researchers can select new areas of the activated regions in order to identify specific missions of the selected parts during real and imaginary movements. Moreover, BCI experiments through a neural prosthesis may be performed to realize the obtained findings.

\section{CONFLICT OF INTEREST}

Author approve that to the best of their knowledge, there is not any conflict of interest or common interest with an institution/organization or a person that may affect the review process of the paper. 


\section{AUTHOR CONTRIBUTION}

Nurhan GÜRSEL ÖZMEN has the full responsibility of the paper about determining the concept of the research, data collection, data analysis and interpretation of the results, preparation of the manuscript and critical analysis of the intellectual content with the final approval.

\section{REFERENCES}

1. Akin, M. and Kiymik, M.K. (2000) Application of periodogram and AR spectral analysis to EEG signals. Journal of Medical Systems, 24,247-256. doi: 10.1023/a:1005553931564.

2. Ames, K. C., and Churchland, M. M. (2019). Motor cortex signals for each arm are mixed across hemispheres and neurons yet partitioned within the population response. Elife, 8, e46159. doi:10.7554/eLife.46159

3. Baccala, L.A. and Sameshima, K. (2001) Partial directed coherence: a new concept in neural structure determination. Biol. Cybern, 84, 463-474. doi: 10.1007/PL00007990

4. Başar, E., Başar-Eroglu, C., Parnefjord, R., Rahn, E., \& Schürmann, M. (1992). Evoked potentials: ensembles of brain induced rhythmicities in the alpha, theta and gamma ranges. In Induced rhythms in the brain Birkhäuser, Boston, MA. (155-181).

5. Bezerianos, A., Stavrinou, M., Cimponeriu, L., \& Moraru, L. (2007). Inferring brain connectivity subserving real and imagined movements from synchronization analysis. Int $J$ Bioelectromagnet, 9(4), 205-13.

6. Binkofski, F. et al. (2002). Neural activity in human primary motor cortex areas $4 \mathrm{a}$ and $4 \mathrm{p}$ is modulated differentially by attention to action. J Neurophysiol, 88, 514-519, doi: 10.1152/jn.00947.2001

7. Birbaumer, N., Hinterberger, T., Kübler A., Neumann N. (2003) The thought-translation device (TTD): Neurobehavioral mechanisms and clinical outcome. IEEE Trans. Neural Syst. Rehabil. Eng., 11, 120-123. doi: 10.1109/TNSRE.2003.814439.

8. Bundy D.T. et al., (2018) Unilateral, three-dimensional arm movement kinematics are encoded in ipsilateral human cortex,, The Journal of Neuroscience, 21,38(47),1004210056 doi.org/ 10.1523/JNEUROSCI.0015-18.2018.

9. Cheyne, D., Bakhtazad, L. \& Gaetz, W. Spatiotemporal mapping of cortical activity accompanying voluntary movements using an event-related beamforming approach. Hum. Brain Mapp.,27, 213-229, doi: 10.1002/hbm.20178 (2006).

10. Daly, I., Nasuto, S. J., Warwick, K., (2012) Brain computer interface control via functional connectivity dynamics, Pattern Recognition, 45, 2123-2136. doi.org/10.1016/j.patcog.2011.04.034.

11. Dauwels J, Vialatte F, Musha T, Cichocki A (2010b) A comparative study of synchrony measures for the early diagnosis of Alzheimer's disease based on EEG. Neuroimage, 49, 668693. doi: 10.1016/j.neuroimage.2009.06.056

12. Fu, R., Wang, H., Bao, T., \& Han, M. (2020). EEG intentions recognition in dynamic complex object control task by functional brain networks and regularized discriminant analysis. Biomedical Signal Processing and Control, 61, 101998. doi: 10.1016/j.bspc.2020.101998

13. Galambos, R., Makeig, S., Talmachoff, P. (1981), A $40 \mathrm{~Hz}$ auditory potential recorded from the human scalp, Proc Natl Acad Sci USA, 78 2643-2647. doi: 10.1073/pnas.78.4.2643 
14. Gao, Q., Duan, X., \& Chen, H. (2011). Evaluation of effective connectivity of motor areas during motor imagery and execution using conditional Granger causality. Neuroimage, 54(2), 1280-1288. doi: 10.1016/j.neuroimage.2010.08.071.

15. Gentili, R. Cahouet, V. Ballay, Y. Papaxanthis, C. (2004) Inertial properties of the arm are accurately predicted during motor imagery, Behav Brain Res, 155, 231-239. doi: 10.1016/j.bbr.2004.04.027

16. Georgopoulos, A. P., Lurito, J. T., Petrides, M., Schwartz, A. B. \& Massey, J. T. (1989). Mental rotation of the neuronal population vector. Science, 243, 234-236, doi: $10.1126 /$ science. 2911737 .

17. Güntekin, B., Başar, E. (2010). A new interpretation of $P 300$ responses upon analysis of coherences. Cognitive neurodynamics, 4(2), 107-118. https://doi.org/10.1007/s11571-0109106-0.

18. Güntekin, B., Femir, B., Gölbaşı, B. T., Tülay, E., \& Başar, E. (2017). Affective pictures processing is reflected by an increased long-distance EEG connectivity. Cognitive neurodynamics, 11(4), 355-367. https://dx.doi.org/10.1007/s11571-017-9439-z.

19. Halliday DM, Rosenberg JR, Amjad AM, Breeze P, Conway BA, Farmer SF (1995) A framework for the analysis of mixed time series/point process data-theory and application to the study of physiological tremor, single motor unit discharges and electromyograms. Prog Biophys Mol Biol 64(2),237-278. doi:10.1016/s0079-6107(96)00009-0

20. Holsheimer, J., \& Feenstra, B. W. A. (1977). Volume conduction and EEG measurements within the brain: A quantitative approach to the influence of electrical spread on the linear relationship of activity measured at different locations. Electroencephalography and clinical neurophysiology, 43(1), 52-58. doi:10.1016/0013-4694(77)90194-8.

21. Kilner, J. M., Paulignan, Y., Boussaoud, D. (2004). Functional connectivity during real vs imagined visuomotor tasks: an EEG study. Neuroreport, 15(4), 637-642. doi: 10.1097/00001756-200403220-00013

22. La Rocca,D., Campisi, P., Vegso, B., Cserti, P., Kozmann, G., Babiloni, F., Fallani, F.D. (2014) Human brain distinctiveness based on EEG spectral coherence connectivity. IEEE transactions on Biomedical Engineering, 61(9), 2406-12. doi:10.1109/TBME.2014.2317881.

23. Li, P., Liu, H., Si, Y., Li, C., Li, F., Zhu, X., ... \& Xu, P. (2019). EEG based emotion recognition by combining functional connectivity network and local activations. IEEE Transactions on Biomedical Engineering, 66(10), 2869-2881. doi: 10.1109/tbme.2019.2897651.

24. Lima, C. F., Krishnan, S., \& Scott, S. K. (2016). Roles of supplementary motor areas in auditory processing and auditory imagery. Trends in neurosciences, 39(8), 527-542. doi:10.1016/j.tins.2016.06.003.

25. Lopes da Silva, F. (2013). EEG and MEG: relevance to neuroscience. Neuron, 80, 11121128. doi: 10.1016/j.neuron.2013.10.017.

26. Mamashli, F., Hämäläinen, M., Ahveninen, J. et al. (2019) Permutation Statistics for Connectivity Analysis between Regions of Interest in EEG and MEG Data. Sci Rep 9, 7942. https://doi.org/10.1038/s41598-019-44403-z

27. Manganotti, P., Gerloff, C., Toro, C., Katsuta, H., Sadato, N., Zhuang, P. A., ... \& Hallett, M. (1998). Task-related coherence and task-related spectral power changes during sequential finger movements. Electroencephalography and Clinical Neurophysiology I Electromyography and Motor Control, 109(1), 50-62. 
28. Matyas, F. et al. (2010). Motor control by sensory cortex. Science 330, 1240-1243, doi: $10.1126 /$ science. 1195797.

29. Miller, K. J. et al. (2010). Cortical activity during motor execution, motor imagery, and imagery-based online feedback. Proc. Natl. Acad. Sci., 107, 4430-4435, doi: 10.1073/pnas.0913697107.

30. Mühl C, Allison B, Nijholt A, Chanel G (2014) A survey of affective brain computer interfaces: principles, state-of-the-art, and challenges, Brain-Computer Interfaces, 1(2), 6684, doi: 10.1080/2326263X.2014.912881.

31. Neuper, C., Müller-Putz, G.R., Scherer, R., Pfurtscheller, G. (2006) Motor imagery and EEGbased control of spelling devices and neuroprostheses. Prog. Brain Res. 159, 393-409. doi: $10.1016 /$ S0079-6123.

32. Nicolelis, M. A. (2003). Brain-machine interfaces to restore motor function and probe neural circuits. Nat. Rev. Neurosci., 4, 417-422, doi:10.1038/nrn1105.

33. Nunez, P.L, Wingeier, B.M, Silberstein, R.B. (2001) Spatial-temporal structures of human alpha rhythms: theory, microcurrent sources, multiscale measurements, and global binding of local networks. Hum Brain Mapp, 13,125-164. doi: 10.1002/hbm.1030.

34. Nunez, P.L, Srinivasan, R., Westdorp, A.F., Wijesinghe, R.S., Tucker, D.M., Silberstein, R.B, Cadusch, P.J. (1997) EEG coherency: I: statistics, reference electrode, volume conduction, laplacians, cortical imaging, and interpretation at multiple scales. Electroencephalogr Clin Neurophysiol, 103(5),499-515. doi:10.1016/S0013-4694(97)00066-7.

35. Ozel, P., Akan, A., \& Yilmaz, B. (2019). Synchrosqueezing transform based feature extraction from EEG signals for emotional state prediction. Biomedical Signal Processing and Control, 52, 152-161. doi: 10.1016/j.bspc.2019.04.023.

36. Ozmen, N.G, Gumusel, L. (2013) Classification of real and imaginary hand movements for a BCI design. 36th IEEE International Conference on Telecommunications and Signal Processing (TSP), Rome, (607-611). ISBN 978-1-4799-0402-0.

37. Ozmen, N.G, Gumusel L, Yang Y. (2018) A Biologically Inspired Approach to Frequency Domain Feature Extraction for EEG Classification. Computational and Mathematical Methods in Medicine. 2018, 1-10. doi:10.1155/2018/9890132

38. Pereda, E., Quiroga, R.Q., Bhattacharya, J. (2005) Nonlinear multivariate analysis of neurophysiological signals. Prog Neurobiol ,77,1-37. doi: 10.1016/j.pneurobio.2005.10.003

39. Personnier, P., Ballay, Y., Papaxanthis, C. (2010). Mentally represented motor actions in normal aging: III. Electromyographic features of imagined arm movements. Behavioural brain research, 206(2), 184-191. doi.org/10.1016/j.bbr.2009.09.011.

40. Sannita, W. G., Lopez, L., Piras, C., \& Di Bon, G. (1995). Scalp-recorded oscillatory potentials evoked by transient pattern-reversal visual stimulation in man. Electroencephalography and Clinical Neurophysiology/Evoked Potentials Section, 96(3), 206-218. doi: 10.1016/0168-5597(94)00285-m.

41. Sasai, S., Koike, T., Sugawara, S. K., Hamano, Y. H., Sumiya, M., Okazaki, S., ... \& Sadato, N. (2020). Frequency-specific task modulation of human brain functional networks: A fast fMRI study. NeuroImage, 224, 117375. DOI: 10.1016/j.neuroimage.2020.117375.

42. Seeber, M., Cantonas, L., Hoevels, M. et al. Subcortical electrophysiological activity is detectable with high-density EEG source imaging. Nat Commun, 10, 753 (2019). doi:10.1038/s41467-019-08725-w. 
43. Seleznov, I., Zyma, I., Kiyono, K., Tukaev, S., Popov, A., Chernykh, M, and Shpenkov, O. (2019) Detrended Fluctuation, Coherence, and Spectral Power Analysis of Activation Rearrangement in EEG Dynamics During Cognitive Workload. Front. Hum. Neurosci. 13, 270. doi: 10.3389/fnhum.2019.00270

44. Sleight, J., Pillai, P., \& Mohan, S. (2009). Classification of executed and imagined motor movement EEG signals. Ann Arbor, University of Michigan, 1-10.

45. Sugata, H., Hirata, M., Yanagisawa, T., Matsushita, K., Yorifuji, S., \& Yoshimine, T. (2016). Common neural correlates of real and imagined movements contributing to the performance of brain-machine interfaces. Scientific reports, 6, 24663. doi: 10.1038/srep24663.

46. Tang, Z., Yu, H., Lu, C., Liu, P., \& Jin, X. (2019). Single-Trial Classification of Different Movements on One Arm Based on ERD/ERS and Corticomuscular Coherence. IEEE Access, 7, 128185-128197.

47. Tzelepi, A. Bezerianos, T. Bodis-Wollner, I. (2000) Functional properties of sub-bands of oscillatory brain waves to pattern visual stimulation in man., Clinical Neurophysiology, 111(2), 259-269. doi:10.1016/S1388-2457(99)00248-5.

48. URL 1: https://brainconnection.brainhq.com/2013/03/05/the-anatomy-of-movement/ (Accessed in:17.07.2020)

49. URL 2: http://www.soft-dynamics.com (Accessed in: 17.07.2020).

50. Wang, X. W., Nie, D., \& Lu, B. L. (2014). Emotional state classification from EEG data using machine learning approach. Neurocomputing, 129, 94-106. doi.org/10.1016/j.neucom.2013.06.046.

51. Wang, R., Wang, J., Yu, H., Wei, X., Yang, C., \& Deng, B. (2015). Power spectral density and coherence analysis of Alzheimer's EEG. Cognitive neurodynamics, 9(3), 291-304. doi: 10.1007/s11571-014-9325-X.

52. Wolpaw, J.R. Birbaumer N., Heetderks W.J., et al, ,(2000) Brain-computer interface technology: A review of the first international meeting. IEEE Trans. Rehab. Eng., 8(2),164173. doi: $10.1109 /$ tre.2000.847807.

53. Yang, L., Lu, Y. (2018) EEG Neural Correlates of Self-Paced Left- and Right-Hand Movement Intention during a Reaching Task, Annual International Conference of the IEEE Engineering in Medicine and Biology Society Conference Proceedings. doi:10.1109/EMBC.2018.8512725.

54. Yong X, Menon C., (2015) EEG Classification of Different Imaginary Movements within the Same Limb. PLoS ONE 10(4): e0121896. doi:10.1371/journal.pone.0121896

55. Zhang, Y., and Zhao, Y. (2013). Real and imaginary modulation spectral subtraction for speech enhancement. Speech Communication, 55(4), 509-522. doi: 10.1016/j.specom.2012.09.005. 